\title{
Small Intestinal Bacterial Overgrowth in Seven Dogs with Gastrointestinal Signs
}

In small intestinal bacterial overgrowth (SIBO) syndrome the small intestine is colonized by bacteria in excess of $10^{5}$ colony-forming units (CFU)/ml or g (Batt et al. 1983, Williams et al. 1987, Strombeck \& Guilford 1990). In dogs, SIBO has only recently been recognized as a cause of gastrointestinal signs like diarrhea (Strombeck et al. 1981, Batt et al. 1983, Batt \& McLean 1987, Batt et al. 1988). No demonstrable underlying anatomic or functional predisposition is identified in most cases of canine SIBO. However, most of the reported cases have been on German shepherds and dogs suffering from pancreatic insufficiency (Williams et al. 1987; Simpson et al. 1990).

In the present study we describe the clinical signs, bacterial intestinal contents, and effect of treatment in 7 dogs with chronic gastrointestinal signs where SIBO was suspected. All were large breed dogs aged 2-8 years and representing 5 different breeds. Only 1 was a female. Control animals were represented by 6 clinically healthy dogs of 5 different breeds aged 1-4 years.

Data on the dogs with chronic gastrointestinal signs were obtained by performing a complete blood count, routine serum chemistry, urinanalysis, faecal flotation for parasitic ova and faecal trypsin activity was determined by radial enzyme diffusion in a substrate containing agar gel.

Full thickness intestinal biopsy specimens $(n=5)$ were taken from the jejunum $10 \mathrm{~cm}$ distal from the duodenal/jejunal flexure. The samples were fixed in $10 \%$ formaldehyde and embedded in paraffin. Sections $4 \mu \mathrm{m}$ thick were stained routinely with hematoxylin and eosin, van Gieson and periodic acid-Schiff.

The dogs were not given antibiotics for 5 days or food for at least $12 \mathrm{~h}$ before the bacteriological samples were taken from the intestinal lumen. The intestinal fluid samples were taken by laparotomy under general anesthesia by inserting a sterile 14 gauge catheter into the lumen of the intestine. A sample was taken from the jejunum of each dog $10 \mathrm{~cm}$ distal to the duodenal/jejunal flexure. Samples from the middle section of the duodenum and the jejunum were taken from 4 of the sick dogs.

Bacterial samples were immediately transferred to anaerobic packages and cultured within $2 \mathrm{~h}$ in an anaerobic cabinet. The packages were then opened aseptically in the anaerobic cabinet and $1.0 \mathrm{~g}$ of the intestinal content was serially diluted tenfold with sterile $0.1 \%$ peptone water and $0.8 \% \mathrm{NaCl}$. The dilutions ( $0.1 \mathrm{ml}$ each) were applied to duplicate blood agar base (BBL) plates containing $5 \%$ defibrinated bovine blood. Half of the plates were then removed from the anaerobic cabinet and incubated aerobically at $37^{\circ} \mathrm{C}$ for 20 $24 \mathrm{~h}$. The rest of the plates were incubated anaerobically in the cabinet at $37^{\circ} \mathrm{C}$ for $44-48 \mathrm{~h}$. Total aerobic and anaerobic bacteria counts 
were calculated and the bacterial numbers expressed as $\log _{10} \mathrm{CFU} / \mathrm{g}$. Colonies with the highest numbers were identified to the genus level according to standard methods (Bergey et al. 1984 and 1986). The coliform bacterial counts were obtained using Violet Red Bile agar plates (Orion Diagnostica, Finland). These plates were cultured using the pourplate procedure and incubated aerobically at $37^{\circ} \mathrm{C}$ for $20-24 \mathrm{~h}$. Each dilution $(0.1 \mathrm{ml})$ was also spread on Tomato-Rogosa (Merck), Slanetz-Bartelye (Oxoid) and Tryptose Sulfite Cykloserine (Difco) plates. The Tomato-Rogosa plates were incubated in an anaerobic jar at $30^{\circ} \mathrm{C}$ for 5 days and the number of lactic acid bacteria was counted. The Slanetz-Bartelye and Tryptose Sulfite Cykloserine plates were used to estimate the number of colonies of fecal streptococci and Clostridium perfringens respectively. The Slanetz-Bartelye plates were incubated aerobically at $37^{\circ} \mathrm{C}$ for $48 \mathrm{~h}$ and the Tryptose Sulfite Cykloserine plates were incubated in the anaerobic cabinet at $37^{\circ} \mathrm{C}$ for $24 \mathrm{~h}$.

Bacterial numbers were expressed as mean $\log _{10} \mathrm{CFU} / \mathrm{g} \pm \mathrm{SD}$. The Wilcoxon rank test was used in testing whether bacterial counts in the different parts of the small intestine differed significantly from each other. The difference in the total bacterial counts in the diseased and normal dogs was also tested, $\mathrm{p}<0.05$ indicating statistical significance.

The clinical signs were similar in all the dogs investigated. The most prominent sign was chronic diarrhea, which had lasted from a few months to several years. In the beginning diarrhea was intermittent, occurring only a few days each month, but then got progressively worse. In the final stage, many dogs had continuous diarrhea. The episodes started very suddenly, the faeces being watery, voluminous and brown or yellow in color. In 4 dogs vomiting of bile-stained fluid was seen simultane- ously with the diarrhea episodes. The appetite varied from poor to very good. Two dogs had steatorrhea and maldigestion signs resembling dogs suffering from exocrine pancreatic insufficiency. Weight loss was considerable in both cases. Flatulence and borborygmi were noticed in most cases. Halitosis and abdominal pain were seen in 2 dogs. In 2 dogs the haircoat was dry and scaling. With one exception, all dogs were alert.

Changes in the hemogram and routine blood chemistry were small and nonspecific. However, 1 dog had low serum urea and cholesterol and high alanine transaminase values, while 3 dogs had low cholesterol values and 1 dog eosinophilia.

Faecal examinations for parasites were negative in all dogs. Faecal protease activity after feeding with raw soybean meal was high in all dogs, indicating that they were not suffering from exocrine pancreatic insufficiency (Westermarck \& Sandholm 1980).

Biopsies $(n=5)$ indicated no pathological changes in the jejunum except in $1 \mathrm{dog}$, in which moderate villus atrophy and moderate infiltration of the lamina propria with plasma cells and lymphocytes were revealed.

Bacteria identified in the intestinal fluid from both diseased and normal dogs included Staphylococcus aureus, faecal streptococci, coliformic bacteria, Lactobacillus spp., Clostridium perfringens, unclassified Gram negative rods, and unclassified Gram positive cocci.

In the sick dogs the total number of bacteria in the samples from the proximal jejunum ranged from $5.4 \mathrm{CFU} / \mathrm{g}$ to $8.9 \mathrm{CFU} / \mathrm{g}$, the mean value being $6.9 \pm 1.3 \mathrm{CFU} / \mathrm{g}$. In control dogs, however, the mean number of bacteria in the proximal part of the jejunum was $4.0 \pm$ $0.6 \mathrm{CFU} / \mathrm{g}$, which is significantly less than in the diseased dogs.

There was no correlation between the number 
of bacteria and the severity of the clinical signs in the sick dogs.

In 4 dogs, from each of which 3 samples of luminal contents were taken, the mean number of bacteria in the duodenum was $7.0 \pm 1.2$ CFU/g; the number increased to $7.6 \pm 1.2$ $\mathrm{CFU} / \mathrm{g}$ in the proximal jejunum and to $7.7 \pm$ $1.2 \mathrm{CFU} / \mathrm{g}$ in the middle jejunum. However, these numbers did not differ significantly between the 3 intestinal locations.

Most of the sick dogs had been treated previously with different kinds of drugs. The motility changers (loperamide, diphenoxylate), pancreatic enzymes, prednisone, and lactobacillus had little effect on the gastrointestinal signs. Papaya briquettes were used in 4 dogs and in 2 of them these had a beneficial effect. Sucralfate reduced vomiting in 2 dogs.

In the present study treatment was started by changing the diet to rice and cottage cheese. Tylosin was used as the only antibiotic except in $1 \mathrm{dog}$, which received both tylosin and metronidazole. The dose of tylosin was $15 \mathrm{mg} / \mathrm{kg}$ BID during the first week, subsequently reduced to $10 \mathrm{mg} / \mathrm{kg}$ once a day.

The change of diet had little or no effect on the gastrointestinal signs, but with the exception of $1 \mathrm{dog}$, the antibiotic treatment with tylosin had a dramatic effect. Improvement was noted within 1-2 days; diarrhea and vomiting stopped and appetite improved. The treatment had to be continued for several months and $1 \mathrm{dog}$ was on medication for more than 2 years. During treatment, the dogs had no gastrointestinal signs; however, if treatment was discontinued too soon, diarrhea and/or vomiting started within 3-5 days. In 2 dogs, antibiotic treatment could be stopped if the dogs continued to have 2 papaya briquettes twice a day. Tylosin treatment did not cause any side effects.

Currently 4 dogs have been without gastrointestinal signs for more than 6 months since termination of the antibiotic treatment. The dog treated with both tylosin $(15 \mathrm{mg} / \mathrm{kg}$ BID) and metronidazole ( $20 \mathrm{mg} / \mathrm{kg}$ BID) was alert and had a good appetite but still suffering from diarrhea. At the request of the owner the dog was put down and 3 new bacterial samples were taken from the intestine. The number of both aerobes and anaerobes had increased about 100 times compared to the prior samples.

This study emphasizes that SIBO is likely to be an important but usually overlooked condition in many breeds of dog. The method used for diagnosing SIBO in the present study is laborious and impractical for routine use. Therefor an accurate, non-invasive diagnostic method is still needed.

\section{E. Westermarck and $R$. Siltanen}

Department of Medicine, College of Veterinary Medicine, Helsinki, Finland.

\section{R. Maijala}

National Veterinary Institute, Field Department, Helsinki, Finland.

\section{References}

Batt RM, Needham JR, Carter MW: Bacterial overgrowth associated with naturally occurring enteropathy in the German shepherd dog. Vet. Sci.1983, 35, 42-46.

Batt RM, McLean L: Comparison of the biochemical changes in the jejunal mucosa of dogs with aerobic and anaerobic bacterial overgrowth. Gastroenterology 1987, 93, 986-993.

Batt RM, McLean L, Riley JE: Response of the jejunal mucosa of dogs with aerobic and anaerobic bacterial overgrowth to antibiotic therapy. Gut 1988, 29, 473-482.

Bergey DH, Krieg NR, Holt JG: Bergey's Manual of Systematic Bacteriology. 1984 vol. 1. Williams \& Wilkins, Baltimore, MD. USA.

Bergey DH, Krieg NR, Holt JG: Bergey's Manual of Systematic Bacteriology. 1986 vol. 2. Williams \& Wilkins, Baltimore, MD, USA.

Simpson KW, Batt RM, Jones D, Morton DB: Effects 
of exocrine pancreatic insufficiency and replacement therapy on the bacterial flora of the duodenum in dogs. Amer. J. vet. Res. 1990, 51, 203206.

Strombeck DR, Doe H, Jang S: Maldigestion and malabsorption in a dog with chronic gastritis. J. Amer. vet. med. Assoc. 1981, 179, 801-805.

Strombeck $D R$, Guilford WG: Small animal gastroenterology. Second edition. Stonegate Pub- lishing, Davis, Ca. USA. 1990, pp 15-21, 310-313. Westermarck E, Sandholm M: Faecal hydrolase activity as determined by radial enzyme diffusion: a new method for detecting pancreatic dysfunction in the dog. Res. vet. Sci. 1980, 28, 341-346.

Williams DW, Batt RM, McLean L: Bacterial overgrowth in the duodenum of dogs with exocrine pancreatic insufficiency. J. Amer. vet. med. Assoc. 1987, 191, 201-206.

(Received June 26, 1992; accepted August 10, 1993).

Reprints may be requested from: E. Westermarck, Department of Medicine, College of Veterinary Medicine, P.O. Box 6, SF-00581 Helsinki, Finland. 